\title{
Notes on the vocalizations of Bahama Yellowthroat (Geothlypis rostrata)
}

Peter Boesman

In the following we briefly analyze and compare voice of Bahama Yellowthroat (Geothlypis rostrata) and Common Yellowthroat (G. trichas). We also try to quantify the extent of any vocal differences using the criteria proposed by Tobias et al. (2010), as a support for taxonomic review.

We have made use of sound recordings available on-line from Xeno Canto (XC) and Macaulay Library (ML).

Song of Bahama Yellowthroat is a short warbled phrase which basically consists of alternating simple upslurred and downslurred notes. Max. frequency: $4.5-5.2 \mathrm{kHz}$, frequency range or bandwidth $2.0-3.0 \mathrm{kHz}$.

Some examples:
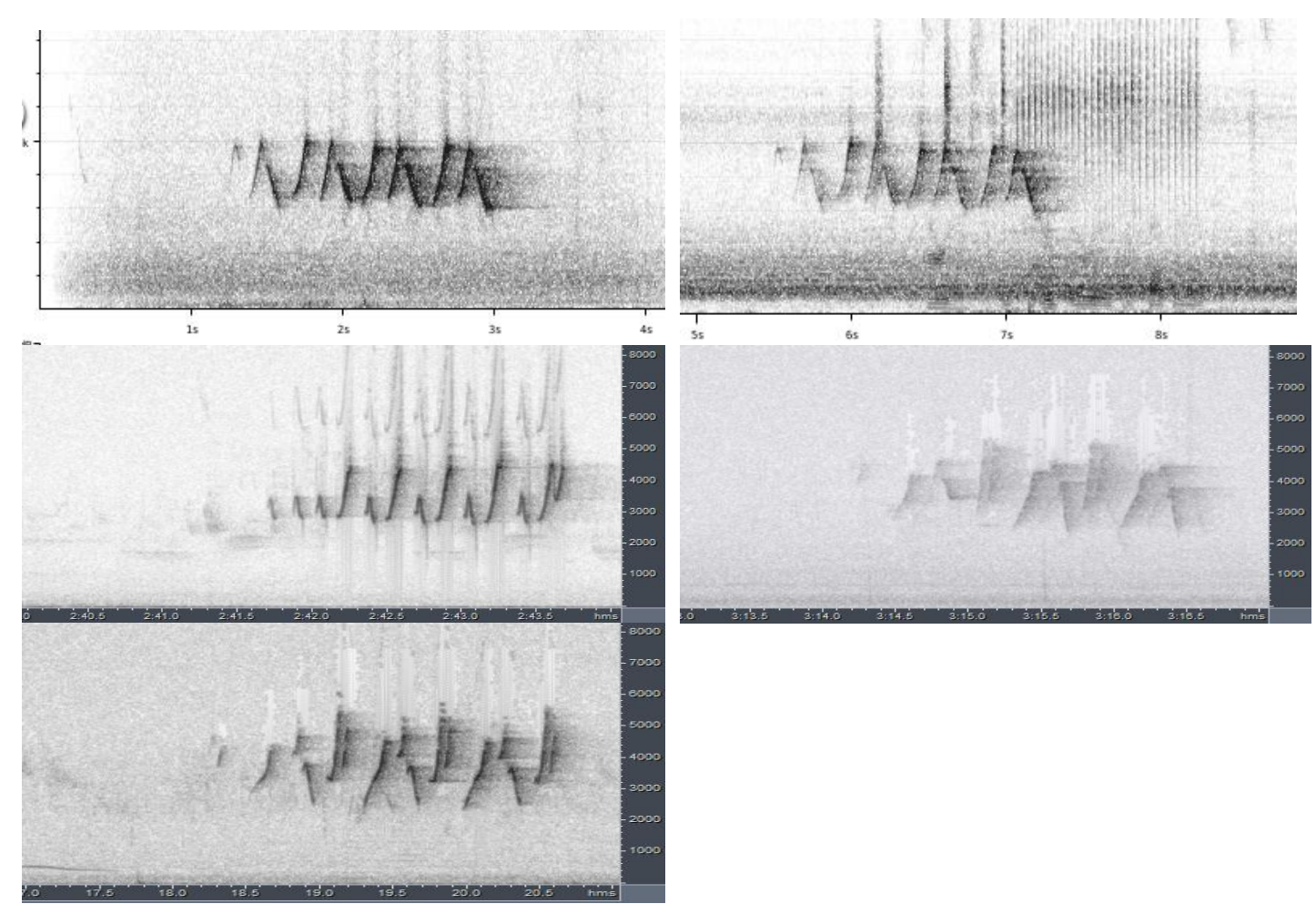

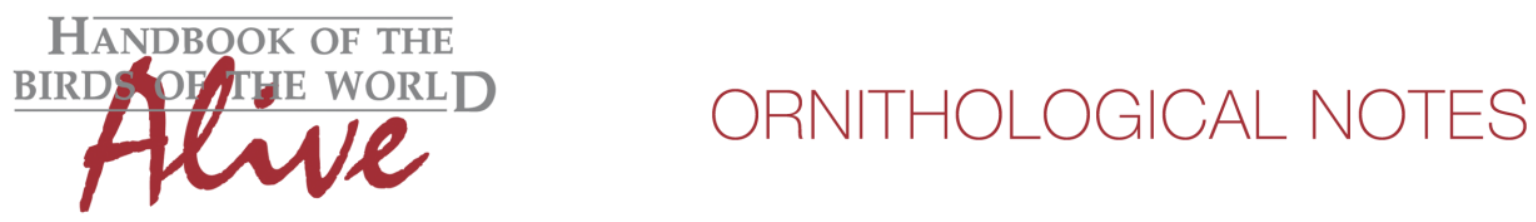

Song of Common Yellowthroat is a short warbled phrase which is quite variable over its large geographical range, but which is always a repeated sub-phrase of several notes. These notes are slightly more complex shaped than $G$. rostrata and reach max. frequency of $5.2-8 \mathrm{kHz}$. Frequency range (bandwidth) is $2.9-5.0 \mathrm{kHz}$.

Some examples:

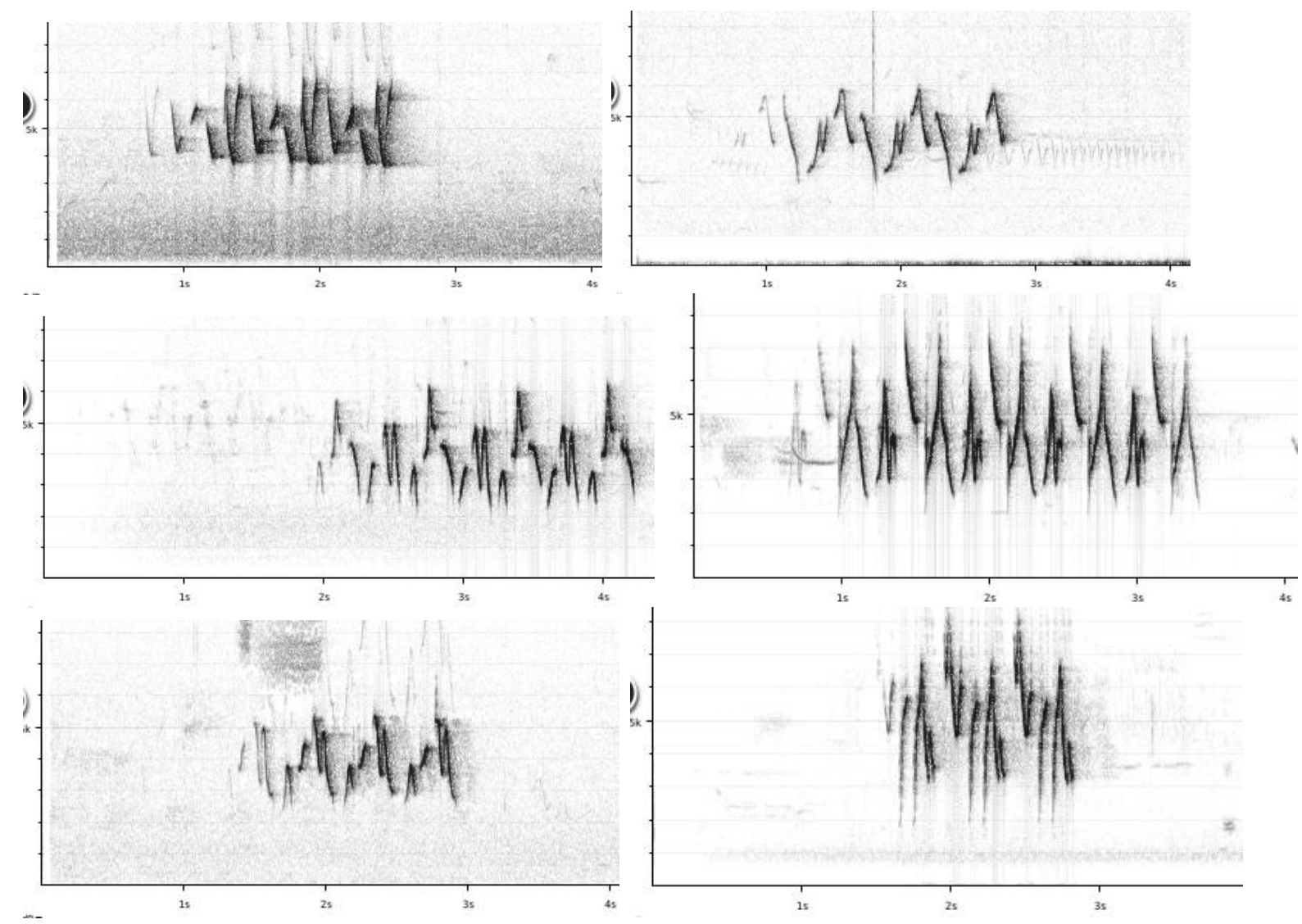

Song of Bahama Yellowthroat has thus a lower max. frequency (score 2), a smaller freq. range or narrower bandwidth (score 2 ) and simpler note shapes (1). When applying Tobias criteria, this would lead to a total vocal score of 4 .

This note was finalized on 24th June 2016, using sound recordings available on-line at that moment. We would like to thank in the many sound recordists who placed their recordings on XC and ML, in particular Paul Dean, Jesse Fagan, Michael Harvey, Peter Kellogg, Linda Macaulay and Douglas Welch for recordings of rostrata.

\section{References}

Tobias, J.A., Seddon, N., Spottiswoode, C.N., Pilgrim, J.D., Fishpool, L.D.C. \& Collar, N.J. (2010). Quantitative criteria for species delimitation. Ibis 152(4): 724-746. 


\section{Recommended citation}

Boesman, P. (2016). Notes on the vocalizations of Bahama Yellowthroat (Geothlypis rostrata). HBW Alive Ornithological Note 371. In: Handbook of the Birds of the World Alive. Lynx Edicions, Barcelona. (retrieved from http://www.hbw.com/node/1252921 on 29 November 2016). 